\title{
Patogenicidade de Corynespora cassiicola em soja, limiares térmicos e temperatura ótima para a germinação de conídios em meio de cultura
}

\author{
Márcia Muliterno de Melo $^{1} \&$ Erlei Melo Reis ${ }^{1,2}$
}

${ }^{1}$ Faculdade de Agronomia e Medicina Veterinária, Departamento de Ftossanidade Universidade de Passo Fundo-, UPF, 99001, Passo Fundo, RS, Brasil.. Bolsista CAPES. ${ }^{2}$ Bolsista do CNPq. Esse trabalho faz parte da dissertação de mestrado de Márcia Muliterno de Melo. Autor para correspondência: Erlei Melo Reis (erleireis@tpo.com.br) Data de chegada: 27/07/2009. Aceito para publicação em: 10/01/2010.

\section{RESUMO}

Melo, M. M. \& Reis, E. M. Patogenicidade de Corynespora cassiicola em soja, limiares térmicos e temperatura ótima para a germinação de conídios em meio de cultura. Summa Phytopathologica, v.36, n.3, p.254-256, 2010.

Ensaios em câmara climatizada e laboratório, foram conduzidos para demonstrar a patogenicidade de Corynespora cassiicola em soja. Para esse estudo, utilizou-se um isolado monosporico obtido de folhas de soja de Primavera do Leste, MT. Os conídios analisados ao microscópio ótico apresentaram morfologia semelhante a do gênero Corynespora. A mensuração de 200 conídios desenvolvidos em meio de cultura, obteve-se as seguintes medidas 8-12 × $20-$ $280 \mu \mathrm{m}$, média de $10 \times 150 \mu \mathrm{m}$. O isolado foi inoculado no cultivar CD 219 RR para comprovar a sua patogenicidade. Pela comparação dos sintomas com as descrições da literatura e pelo reisolamento do patógeno, seguido de sua caracterização morfológica, confirmou-se à patogenicidade do isolado de C. cassiicola. Para identificar os limiares térmicos inferior (Lti) e superior (Lts) e a temperatura ótima e o limiar térmico superior (Lts) para a germinação de esporos de C. cassiicola, foi conduzido um ensaio em placas de Petri, com meio de cultura Czapek ágar. Foram testados: (a) tempo de exposição de 6,12 e 24 horas e (b) temperaturas mínimas de $5,6,7,8,9$ e $10{ }^{\circ} \mathrm{C}$, intermediárias de $15,20,25,30$ e $35^{\circ} \mathrm{C}$ e superiores de $36,37,38,39,40$ e $41^{\circ} \mathrm{C}$. Os dados foram submetidos a análise de variância e regressão. Os conídios germinaram em uma ampla gama de temperatura tendo como valores de Lti $7^{\circ} \mathrm{C}$, ótima de $23^{\circ} \mathrm{C}$ e valores de Lts $39^{\circ} \mathrm{C}$.

Palavras-chave adicionais: Mancha-alvo, soja, temperatura basal, Glycine Max,

\section{ABSTRACT}

Melo, M. M. \& Reis, E. M. Pathogenicity, thermal thresholds and optimal temperature for Corynespora cassiicola conidium germination in culture medium. Summa Phytopathologica, v.36, n.3, p.254-256, 2010

In experiments conducted in a growth chamber, the pathogenicity of a monosporic isolate of Corynespora cassiicola was tested. The isolate was obtained from the leaves of soybean was performed. The isolate of C. cassiicola used was obtained from leaves of soybean from Primavera do Leste, Mato Grosso State, Brazil. The morphology of the conidia under the optical microscope was similar to that of the genus Corynespora. In the assessment of 200 conidia, the following measures were obtained: $8-12 \times 20-280 \mathrm{~m}$, mean of $10 \mathrm{x}$ $150 \mu \mathrm{m}$. The cultivar CD $219 \mathrm{RR}$ was inoculated to prove pathogenicity. Based on the comparison of the symptoms with the descriptions in literature and on the pathogen reisolations followed by its morphological characterization, the pathogenicity of the $C$. cassiicola isolate used in this work is confirmed. To identify the lower (Lti), and upper (Lts) thermal threshold, as well as the optimal temperature, for the germination of spores, an experiment was performed in Petri dishes containing Czapek agar medium. The tested variables were: (a) exposure times of 6, 12 and 24 hours and (b) low temperatures of $5,6,7,8,9$ and $10^{\circ} \mathrm{C}$, intermediate temperatures of $10,15,20,25,30$ and $35^{\circ} \mathrm{C}$, and high temperatures of $36,37,38,39$, 40 and $41^{\circ} \mathrm{C}$. Data were subjected to analysis of variance and regression. The conidia germinated within a wide temperature range presenting Lti of $7^{\circ} \mathrm{C}$, optimal temperature of $23^{\circ} \mathrm{C}$ and Lts of $39^{\circ} \mathrm{C}$.

Keywords: Target leaf spot, soybean, base temperature, Glycine max,

A soja [Glycine $\max (\mathrm{L}$.$) Merr] é uma importante cultura para a$ agricultura brasileira. Na safra 2007/08 foram cultivados 21,3 milhões de ha, com rendimento médio de 2,8 t.ha $^{-1}$ e produção de 60,0 milhões de toneladas, (4).

Embora não tenham sido determinados os danos, entre as doenças que afetam a soja, merece destaque a mancha-alvo, causada pelo fungo Corynespora cassiicola (Berk. \& Curt.) Wei. O primeiro relato da doença na cultura da soja foi feito nos Estados Unidos, em 1945, por Olive (6). No Brasil, a doença foi citada pela primeira vez por J. T. Yorinori no estado do Paraná e em São Paulo, (1). Os autores não descreveram a realização da prova de patogenicidade, apenas a realização de isolamentos e a descrição morfológica do agente causal foi tomada de Olive et al. (6). Portanto, não foram satisfeitos os postulados de Koch descritos por Agrios (3).

Os objetivos deste trabalho foram: (i) confirmar a patogenicidade e identificar o isolado do agente causal da mancha-alvo da soja usado nesta investigação e (ii) identificar o limiar térmico inferior (Lti), a temperatura ótima (To) e o limiar térmico superior (Lts) para a germinação de conídios de de $C$. cassiicola, como primeiro passo na tentativa de modelar a ocorrência da doença por unidades de calor. 


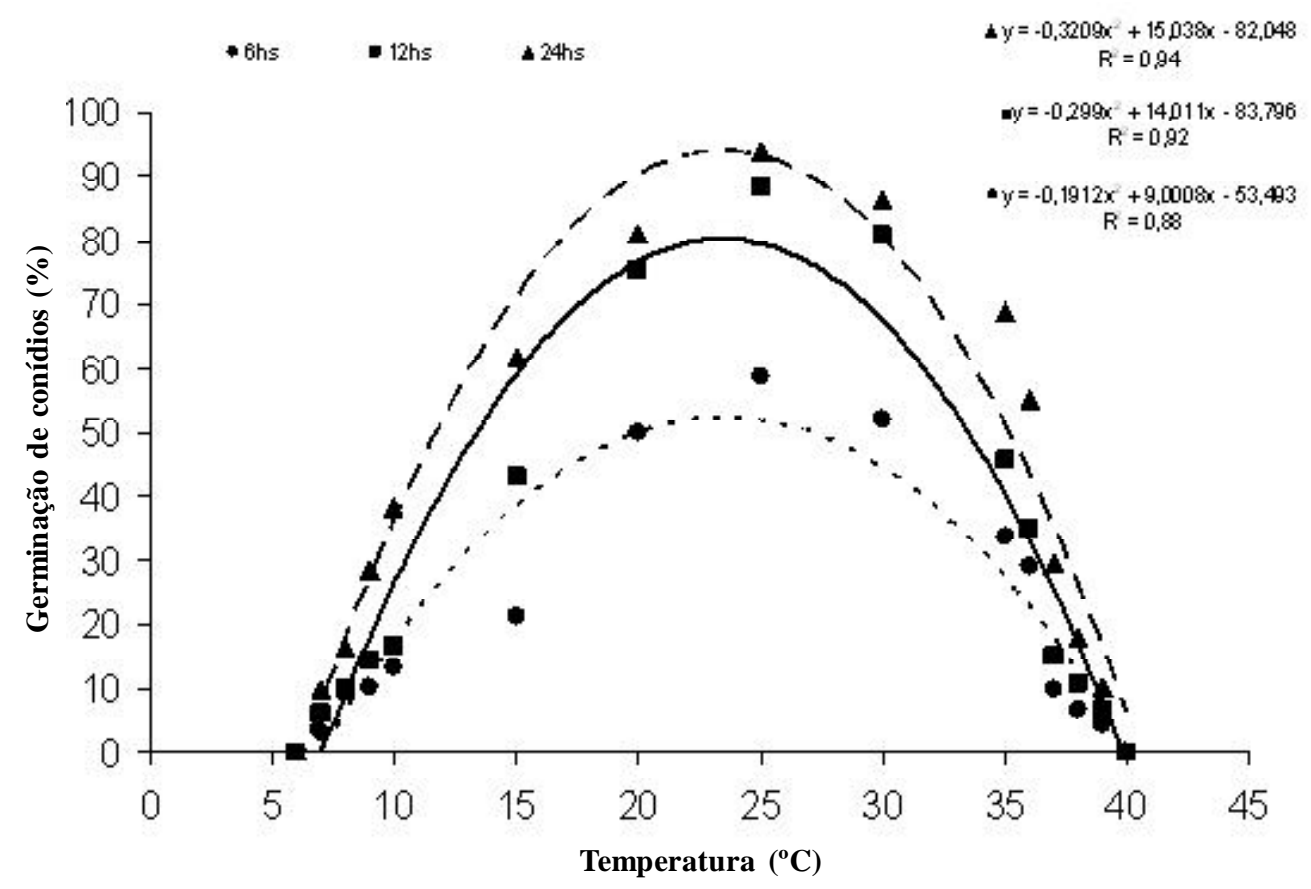

Figura 1. Relação entre germinação de conídios de Corynespora cassiicola, temperaturas e tempos de exposição.

Conídios de um isolado monospórico de Primavera do Leste, MT, foram multiplicados em meio de cultura Czapek contido em placas de Petri plásticas mantidas em câmara de crescimento a $25 \pm 2{ }^{\circ} \mathrm{C}$ e com fotoperíodo de 12 horas durante 20 dias, até obter-se esporulação abundante. A concentração utilizada na inoculação das plantas foi de 4 $\mathrm{x} 10^{4}$ conídios. $\mathrm{mL}^{-1}$. Na suspensão foi adicionado uma gota de espalhante adesivo, Tween 20 (polioxietilenosorbitano). Plantas de soja do cultivar CD 219 RR no estádio V4, cultivadas em vaso, foram inoculadas pela deposição da suspensão do inóculo com aspersor manual sobre as folhas de soja, até o ponto de escorrimento. Outro conjunto de cinco vasos foram atomizados apenas com água e mantidos sob as mesmas condições ambientais, servindo como testemunhas. Após a inoculação, as plantas foram mantidas em câmara úmida por um período de 48 horas e temperaturas de $25{ }^{\circ} \mathrm{C}$. Ao término desse período,as plantas foram retiradas da câmara úmida e foram colocadas em casa de vegetação, esperou-se uma semana até a manifestação dos sintomas. Para completar o teste de patogenicidade reisolou-se o fungo das folhas inoculadas. Após o desenvolvimento da colônia do fungo em meio de cultura BDA e esporulação em câmara úmida, foram preparadas lâminas através do processo de microcultivo, com a finalidade de identificar o agente causal através de suas características morfológicas: forma, tamanho, número de septos, cor dos conídios e coloração das colônias em meio de cultura.

As plantas inoculadas, após o período de incubação de 12 dias apresentaram os sintomas da mancha-alvo. Os sintomas se iniciaram por pontuações pardas, com halo amarelado, evoluindo para manchas circulares, de coloração castanha, atingindo menos de $2 \mathrm{~cm}$ de diâmetro. As manchas apresentaram anéis concêntricos semelhantes a um alvo. Esses sintomas coincidem com os descritos por Snow \& Berggren (8) causados C. cassiicola em plantas de soja. As plantas testemunhas, pulverizadas apenas com água, não apresentaram sintomas.

Os conídios nas lâminas de microcultivo, observados ao microscópio óptico apresentaram morfologia idêntica a do gênero de Corynespora, conídios retos ou ligeiramente curvos, hialinos, subcilíndricos, truncados no hilo basal, a maioria com três septos transversais. $\mathrm{O}$ fungo em meio de cultura BDA apresentou crescimento e esporulação lentos, formando um micélio de tonalidade escura e de coloração cinza-esverdeada a preto- oliváceo, semelhante aos dados descritos por Almeida et al. (2).

Na mensuração de 200 conídios oriundos da esporulação em folhas em câmara úmida verificou-se as dimensões de $8-10$ x $125-210 \mu \mathrm{m}$, com uma média de $9 \times 167,5 \mu \mathrm{m}$, e para os produzidos em meio de cultura BDA as dimensões foram 8-10 x $69-179 \mu \mathrm{m}$.

Os efeitos do tempo de exposição e da temperatura na germinação dos conídios foram determinados num experimento fatorial com quatro repetições. $O$ fator (a) tempo de exposição foi de 6,12 e $24 \mathrm{~h}$ e o fator (b) temperatura compreendeu valores inferiores de 5, 6, 7, 8, 9 e 10 ${ }^{\circ} \mathrm{C}$, intermediários de $10,15,20,25,30$ e $35^{\circ} \mathrm{C}$ ) e superiores de 36 , $37,38,39,40$ e $41{ }^{\circ} \mathrm{C}$. As diferentes temperaturas foram obtidas em incubadoras (BOD - Biological oxigen demand). Utilizou-se o meio de cultura de Czapek- ágar em placas de petri plásticas de $6,0 \mathrm{~cm}$ de diâmetro para quantificar a germinação. Nas placas foi vertido $1,0 \mathrm{~mL}$ de uma suspensão de conídios. Ao findar cada tempo de exposição, o processo de germinação foi paralisado pela adição de $1,0 \mathrm{~mL}$ da mistura acetona-azul de algodão resultando na coloração dos esporos e facilitando a avaliação. A germinação dos conídios foi avaliada em microscópio óptico pela varredura da placa avaliando-se ao acaso 100 esporos por repetição. Considerou-se germinado o conídio que apresentou o tubo germinativo com comprimento pelo menos uma vez mais longo do que a largura de esporo. Os dados foram submetidos à análise da variância e de regressão.

Cada organismo tem uma temperatura basal, uma ótima e um limite térmico superior nas qual o crescimento é paralisado e acima/ abaixo o desenvolvimento é retomado Trudgill et al. (10). Na infecção a temperatura não age isoladamente, mas em interação com a duração do período de molhamento foliar contínuo, Sutton (9). A germinação dos esporos ocorreu na faixa térmica de 7 , a $39^{\circ} \mathrm{C}$, confirmando os relatos de Snow \& Berggren (8). Segundo Ellis (5) e Seaman et al. (7), 
o patógeno se desenvolve na faixa térmica de 18 a $21^{\circ} \mathrm{C}$

Utilizando as equações geradas identificou-se a temperatura ótima para a germinação de $C$. cassiicola de $23^{\circ} \mathrm{C}$. Os esporos germinam em uma ampla gama de temperatura, sendo o valor de Lti $7{ }^{\circ} \mathrm{C}$ e o valor de Lts $39{ }^{\circ} \mathrm{C}$. O valor de temperatura base será usado em estudos para desenvolver um modelo de aviso da doença.

A identificação de $C$. cassiicola foi confirmada por sua prova de patogenicidade, caracterização morfológica e pela comparação com descrições de espécies de $C$. cassiicola disponíveis na literatura.

Não foram encontradas na literatura, as informações detalhadas sobre o efeito da temperatura e tempos de exposição sobre a germinação de conídios de C. cassiicola.

\section{REFÊRENCIAS BIBLIOGRÁFICAS}

1. Almeida, A.M.R.; Machado, C.C.; Ferreira LP.; Lehman, P.S.; Antonio, H. Ocorrência de Corynespora cassiicola (Berk. \& Curt.) Wei no estado de São Paulo. Fitopatologia Brasileira, Brasília, v. n.1, p. 111-112, 1976.

2. Almeida, A.M.R.; Vasconcelos, M.J.V.; Abdelnoor, R.V.; Yorinori, J.T.; Barros, E.G.; Moreira, M.A. Diferenciação de isolados de
Corynespora cassiicola. Fitopatologia Brasileira, Brasília, v.n. 29,supl. p. 316, 1994.

3. Agrios, G.N. Plant pathology. $5^{\text {th }}$ Ed. Amsterdam: Elsevier; Academic Press, 2005.803 p.

4. Companhia Nacional de Abastecimento (Conab). Acompanhamento da safra brasileira de grãos 2007/2008. Disponível em: <www.conab.gov.br/conabweb/download/safra/ 12_levantamento_set2008.pdf >. Acesso em: 05 set.2008.

5. Ellis, M.B. Dematiaceous hyphomicetes. Kew Surrey. Commonwealth Mycological Institute/ CAB, 1971.608p.

6. Olive, L.S. ; Bain, D.C. ; Leuffeura, C.S. A leaf spot of cowpea and soybean caused by an undescribed species of Helminthosporium. Phytopathology, Saint Paul, v.n.35, p.822-831, 1945.

7. Seaman, W.L.; Shoemaker, R.A.; Peterson, E.A. Pathogenicity of Corynespora cassiicola on soybean. Canadian Journal Botany, Guelph, v. 43, p. 1461 - 1469, 1965.

8. Snow, J.P.; Berggren Jr, G.T. Target Spot: Compedium of soybean diseases. Saint. Paul. American Phytopathological Society, 1989, p. 27-28.

9. Sutton, J.C. Predictive value of weather variables in the epidemiology and management of foliar disease. Fitopatologia Brasileira, Brasília, v. 12, p. 305-312, 1988.

10. Trudgill, D.L.; Honek, A.; Li, D.; Van Straalen, N.M. Thermal time - concepts and utility. Annals of Applied Biology. p. 1$14,2005$. 